\title{
Sob o olhar das crianças: o processo de transição escolar da educação infantil para o ensino fundamental na contemporaneidade
}

\author{
Edilamar Borges Dias ${ }^{\mathrm{I}}$ \\ Rosânia Campos ${ }^{\mathrm{II}, \text { III }}$
}

http://dx.doi.org/10.1590/S2176-6681/346813580

\footnotetext{
Mestranda em Educação da Universidade da Região de Joinville (Univille), Joinville, Santa Catarina, Brasil.

E-mail: edilamar.b@hotmail. com

II Programa de Pós-Graduação em Educação da Universidade da Região de Joinville (Univille), Joinville, Santa Catarina, Brasil.

E-mail: rosaniacampos@ univille.br

III Doutora em Educação pela Universidade Federal de Santa Catarina (UFSC), Florianópolis, Santa Catarina, Brasil.
}

\section{Resumo}

Parte de uma pesquisa desenvolvida na rede pública municipal de educação da cidade de Joinville (SC), que tem como objetivo discutir como as crianças vivenciam a passagem da educação infantil para o ensino fundamental. Para tanto, desenvolveu-se, com um grupo de crianças que frequentavam o último período da educação infantil, uma pesquisa etnográfica, iniciada em 2013 e concluída em 2014, quando esse mesmo grupo de crianças já havia ingressado no $1^{\circ}$ ano do ensino fundamental. Para coleta de dados, foi utilizada a observação participante, o registro em diário de bordo e o registro fotográfico. Os dados foram analisados tendo como base o diálogo com as contribuições de diferentes teóricos da educação, dos estudos provenientes da sociologia da infância e da psicologia sócio-histórica. As análises evidenciaram que, embora muitas das práticas da educação infantil sejam incorporadas pela escola, os modos como são desenvolvidas e como são concebidas pela escola resultam em interações diferentes com as crianças. Nesse sentido, as crianças indicam que, mesmo desejando entrar no ensino fundamental, estar na escola é um desafio diário.

Palavras-chave: políticas públicas para educação; educação infantil; ensino fundamental; prática pedagógica. 


\title{
Abstract \\ Under the gaze of children: the school transition from early childhood education to elementary school in the contemporaneity
}

This article is part of a research developed at the public education network in the city of Joinville (in the state of Santa Catarina) and aims at discussing how children experience the transition from kindergarten to primary school. In order to achieve this goal, we developed an ethnographic research that began in 2013, with a group of children who attended the last year of early childhood education. The study was concluded in 2014, when this same group of children had been attending the first grade of primary school. The instruments for data collection counted on participant observation, records on a logbook, and photographic registers. The data were analyzed according to the dialogue based on contributions of different educational theorists, studies related to childhood sociology and to sociohistorical psychology. The analyses showed that, despite many of the practices of early childhood education being incorporated in the school, the ways they are developed and how they are conceived by the school result in different interactions among the children. In that sense, the children indicate that being at school is a daily challenge, even when they are willing to enter elementary school.

Keywords: public policies for education; early childhood education; elementary school; pedagogical practice.

\author{
Eu vou pro primeiro ano, \\ a, minha mãe já me matriculou! \\ E porque também \\ vou fazer seis anos, né? \\ Agora tenho que ir lá e vou \\ pra aquela escola ali, oh! \\ (Joaquim, 5 anos - 2013)
}

Ainda é um grande desafio considerar a infância não apenas como mera fase do desenvolvimento do ser humano, mas como construção cultural, permeada por diferentes experiências e engendrada nas relações com o meio e com o Outro. Seguindo essa perspectiva, entendemos que a criança produz e concebe o mundo com base em suas relações sociais, relações estas sempre mediadas por um Outro. Considerando essa definição de infância, o objetivo deste estudo é procurar apreender a "voz das crianças na singularidade de suas tessituras" (Carvalho; Müller, 2010, p. 67), nos modos como vivem seu tempo nos espaços educativos. Mais especificamente, observar-se-á como as crianças vivenciam a passagem da educação infantil para o ensino fundamental. Nesse sentido, é interessante ressaltar que este trabalho tem como norte a perspectiva de investigar o ponto de vista das próprias crianças, sem subestimar suas ações ou percebê-las com base em concepções do mundo adulto acerca das necessidades infantis. 
Desse modo, este estudo não pretende discutir o modo pelo qual a infância e as crianças são vistas pelos professores; este artigo não propõe a investigação que tem como enfoque o olhar do adulto sobre as ações e falas infantis. A intenção é discutir que, envolvidas nas práticas sociais juntamente com os adultos e seus pares, as crianças constroem sua identidade e seus modos de ser e estar nesse mundo. Baseando-se nessas considerações, optou-se pela abordagem etnográfica, tendo em vista a necessidade de apreender o cotidiano das instituições educativas pelo olhar das crianças, bem como o entendimento de que essa abordagem oportuniza melhor aproximação em relação a esses sujeitos.

Nesse processo, de acordo com Lüdke e André (1986, p. 90):

[...] o pesquisador deve estar sempre atento à acuidade e à veracidade das informações que vai obtendo, ou melhor, construindo. Que ele coloque nessa construção toda sua inteligência, habilidade técnica e uma dose de paixão para temperar (e manter a têmpera!). Mas que cerque o seu trabalho com o maior cuidado e exigência, para merecer a confiança dos que necessitam dos seus resultados.

Após a definição da metodologia da pesquisa e dos instrumentos de coleta de dados, definiu-se a forma com que os dados seriam analisados. Desse modo, para a coleta, utilizou-se: anotações em diário de bordo, entrevista com as crianças, observação participante e registro fotográfico. Os dados foram analisados segundo a teoria da Análise de Discurso Textualmente Orientada (ADTO), de Norman Fairclough (2001). A escolha dessa teoria é justificada pelo fato de tratar os dados discursivos como resultados de condições sociais, políticas e ideológicas contidas na linguagem. De acordo com esse autor, a análise crítica do discurso é uma ferramenta importante no processo emancipatório do sujeito, uma vez que a linguagem produz efeito tanto de controle quanto de dominação social. Nesse sentido, utiliza-se uma perspectiva tridimensional para a análise do discurso, isto é, considera-se o texto, o contexto (as práticas discursivas) e as práticas sociais.

Tomando como base os estudos de Fairclough (2001) e as contribuições da sociologia da infância, de teóricos da educação e da psicologia sóciohistórica, foi possível analisar os dados mediante uma leitura crítica, considerando o contexto histórico e social dos sujeitos envolvidos. Entende-se que crianças falam e se expressam não apenas por palavras, mas também por gestos, expressões, mímicas e outras linguagens tão presentes na infância. Além desse aspecto, entendemos ainda que tanto o tipo de pesquisa escolhido como o modo de análise dos dados oportuniza pensar o real para além de sua aparência, proporcionando um papel ativo ao pesquisador, que deve apreender a essência do fenômeno, sua estrutura e sua dinâmica. Em outras palavras, essas opções metodológicas propiciam

A presente pesquis foi submetida e aprovada no comitê de ética da Universidade da Região de Joinville (Univille/SC). pensar o fenômeno em seu processo.

Assim, a presente pesquisa ${ }^{1}$ foi desenvolvida em duas instituições educativas públicas municipais na cidade de Joinville (SC), sendo uma instituição de educação infantil e outra de ensino fundamental. O período 
de coleta de dados ocorreu no segundo semestre de 2013 e participaram 24 crianças que frequentavam o último período da educação infantil. A investigadora frequentava a instituição uma vez na semana, no entanto, nos meses de setembro a dezembro, por vezes, a frequência no campo correspondia a dois dias na semana. Esse processo de coleta foi concluído entre os meses de fevereiro e abril de 2014, com o mesmo grupo de crianças que, naquele momento, frequentava o $1^{\circ}$ ano de uma escola de ensino fundamental. A frequência semanal foi mantida e, por vezes, a pesquisadora participava de eventos e/ou encontros na instituição. É importante observar que, antes do início da coleta de dados junto às crianças, foi realizado um contato com a Secretaria Municipal de Educação (SME) a fim de apresentar a pesquisa e conseguir autorização para entrar em contato com as instituições que seriam os espaços da investigação. Na sequência, após a aprovação da SME, a pesquisadora realizou reuniões com as direções das instituições para explicitar o objetivo e os procedimentos da pesquisa. Após essa reunião e o aceite das instituições, antes de iniciar o contato direto com as crianças, foi realizado um encontro com os pais para discutir a pesquisa e solicitar autorização tanto da imagem quanto das falas dos sujeitos. De posse de todas as autorizações, a pesquisadora teve um primeiro encontro com o grupo de crianças para apresentar, discutir e solicitar a participação na pesquisa. Nesse processo, em consonância com famílias e crianças, optou-se por manter os nomes verdadeiros e, assim, garantir suas autorias.

O presente trabalho é organizado em três seções: discussão de como as crianças justificam o ingresso no ensino fundamental; análise de como vivenciam o estar na escola e das estratégias que criam nesse contexto; e considerações sobre esse processo de transição.

"Tô crescendo! Por isso vou pra aquela escola ali!": como as crianças compreendem a entrada no ensino fundamental

A passagem da criança da educação infantil para o ensino fundamental se caracteriza pela força cultural do mundo letrado na sociedade. Em busca não somente da razão de ser, mas de muitas outras razões da própria existência humana, as crianças ingressam no universo escolar cheias de expectativas. Nesse contexto, elas interagem com o novo, com o inesperado, e experimentam as vivências mais variadas possíveis dentro do próprio grupo, com os adultos, os espaços e os objetos que constituem esses espaços. Elas trocam conhecimentos sobre os acontecimentos que as rodeiam e as percepções acerca dos fatos de seu cotidiano. Criam e recriam situações, trocam risos e afetos, curiosidades e medos, dúvidas e incertezas do desconhecido, bem como falam e agem com simplicidade. Foi com esse espírito curioso que, ao findar o ano de 2013, as crianças perceberam que o próximo ano suscitaria outras experiências, bem diferentes das praticadas até então, como a possibilidade de fazer novos amigos.

Quando as crianças ainda estavam na educação infantil, uma das questões direcionadas a elas era por que mudariam de escola. A resposta 
de Gabriela foi a seguinte: "tô crescendo! Por isso vou pra aquela escola ali" (apontando para a escola ao lado do Centro de Educação Infantil - CEI). Para Felipe, Henrique e Rafael, a ida para o ensino fundamental se justificava pelo fato de já terem feito seis anos e não poderem mais ficar na educação infantil, pois, aos seis anos, devem ir para a escola de ensino fundamental. De acordo com Joaquim, ir para a escola significava aprender a ler e a escrever, afirmativa preponderante no discurso da maioria das crianças.

O domínio da escrita era considerado uma necessidade, tendo em vista que estavam "crescendo" ou que "estavam grandes". Esse fato nos fez perceber que, segundo as crianças, a ida para escola era muito mais do que troca de espaço ou submissão a novas regras; era como um "passaporte" para um universo a que elas ainda não tinham acesso ou não tinham reconhecido o acesso, isto é, segundo suas perspectivas, quando as crianças entravam na escola, entravam também no mundo letrado dos adultos.

De acordo com Sacristán (2005, p. 182),

[...] as práticas de leitura e escrita nas escolas adquirem formas e um significado especial; por isso socializam o leitor-aluno de uma forma singular. As modalidades de ler e escrever nas salas de aula se constituem em modos de ter acesso à cultura e em modos de ser pessoa.

Dito de outro modo, ir para a escola de ensino fundamental significava, para as crianças da educação infantil, mais do que estar crescendo, conforme discutido anteriormente; significava fazer parte do mundo letrado.

Essa entrada autorizada é também reforçada pelos discursos dos adultos que rodeiam as crianças, como se pode observar na fala de Joaquim:

Quando começar a copa do mundo a gente já vai tá lendo e escrevendo. A pesquisadora, então, perguntou a ele: quem disse que até a copa do mundo você já vai saber ler e escrever? Joaquim prontamente respondeu: Foi a minha mãe. (Diário de Bordo, 2014).

Ainda seguindo esse diálogo, a pesquisadora questionou:

Joaquim, você gosta mais aqui da escola ou mais do CEI? Joaquim novamente responde: Daqui [escola], porque aqui... a gente faz bastante coisa, a gente faz muito mais coisa do que lá. Aqui a gente vai saber ler e escrever. Ah! Lá no jardim também é legal, tem o parque, né? Mas aqui vou aprender mais coisas. Foi a minha mãe que falou! Ah! Tem as tarefas também, que eu adoro, né? (Diário de Bordo, 2014).

A fala de Joaquim ilustra, entre outros aspectos, a grande expectativa dos pais em relação ao ato de ler e escrever e reforça a secundarização das demais atividades, como a brincadeira e outros modos de aprender. Essa força do mundo letrado e das concepções acerca da importância dessa aprendizagem se fazia presente também no contexto da educação infantil; é possível, no entanto, perceber que, no universo da educação infantil, a relação com a escrita seguia a ordem social tradicional, para a qual a escrita simboliza poder, assim como mais uma experiência do cotidiano. Desse modo, comumente as crianças pediam para manusear e escrever no diário de bordo da pesquisadora. 
Nesse processo, em vários momentos, era visível que as crianças modificavam sua postura física. Por exemplo, as meninas ficavam sentadas com as pernas cruzadas, como as mulheres adultas costumam sentar. Seguravam o diário e escreviam nele, de modo que pareciam remeter-se a algo "muito sério". Elas ficavam compenetradas nessa atividade, de forma que, mesmo estando no parque, sua atenção concentrava-se no caderno. A preocupação não era codificar e decodificar; era procurar compreender o instrumento e seu uso na sociedade.

É interessante observar que, mesmo as crianças interagindo com cadernos, letras e livros no cotidiano da educação infantil, suas falas nos indicavam que não entendiam isso como processo de aquisição de linguagem escrita. Pelo contrário, as falas denotavam que essa apropriação só seria realizada após o ingresso no $1^{\circ}$ ano. Assim, parece que a sistematização realizada no ensino fundamental, bem como a histórica representação desse nível educativo como locus de alfabetização, gerou nas crianças as expectativas de ingressarem logo na escola. Nesse sentido, faz-se importante compreender esses desejos, lembrando que, como bem pontuou Paulo Freire (2013), em uma cultura letrada, aprender a ler e a escrever significa fazer parte da cultura presente na sociedade em que os sujeitos estão inseridos. A intenção última desse aprendizado vai além da alfabetização, pois sua relevância está no fato de se fazer parte do mundo letrado. Desse modo, para as crianças pesquisadas, é deveras significativo estar na escola de ensino fundamental, visto que elas sabem que, nesse contexto, as aprendizagens direcionadas para aquisição da escrita tornam-se reconhecidas como tais. Por um lado, as falas das crianças nos indicam a importância de frequentar a escola e sua ansiedade em participar "desse mundo"; por outro, suas condutas e relações no cotidiano do ensino fundamental vão nos indicando como essa tarefa é ainda sofrida para muitas delas. O modo como as crianças vivenciam o estar na escola e suas estratégias nesse contexto é objeto de nossa próxima discussão.

\section{"Estamos agora no primeiro ano, aqui é pra aprender a ler e escrever! Vocês não são mais bebês, já são grandes!". O cotidiano no ensino fundamental}

Na escola de ensino fundamental, as crianças, agrupadas, estavam curiosas pelo novo, pelo ambiente diferente daquele a que estavam acostumadas até então. Com o início das atividades em sala de aula, as crianças se deram conta de que agora o tempo de permanência na instituição escolar era utilizado de forma diferente do que na educação infantil. Nos primeiros dias de aula, as crianças perguntavam à professora a que horas iriam brincar e qual era a hora de irem ao parque. A resposta da professora do primeiro ano, em geral, era:

- Calma, calma! Estamos agora no primeiro ano, aqui é pra aprender a ler e escrever! 
- Vocês não são mais bebês, já são grandes!

- Vocês vão ver só como é bom aprender essas coisas!

- Quando já souberem ler e escrever, vão até me agradecer. (Diário de

Bordo, 2014).

A professora, com olhar determinante, com sorriso nos lábios, confirmava sua fala, balançando a cabeça afirmativamente.

Ao analisar esse discurso, percebe-se o quanto está implícito o não reconhecimento das atividades desenvolvidas na educação infantil e a ratificação de que naquele momento eles iriam aprender a ler e escrever. Em outras palavras, as aprendizagens relacionadas às interações das crianças com o brincar foram relegadas a segundo plano, consideradas de menor importância. Essa concepção acaba por reafirmar a histórica divisão entre educação infantil e ensino fundamental, da qual as crianças se apropriam, de modo que, com base nessa divisão, o pensamento sequencial, linear, formulado segundo causa e efeito, é difundido.

Nesse processo, a brincadeira, que proporciona à criança as mais variadas significações, gerando diversos tipos de conhecimento, de forma individual e/ou coletiva, é negada ou permitida apenas em determinados momentos. Assim, a fala da professora e suas ações no cotidiano da sala evidenciaram fragilidade na apropriação da brincadeira como grande mediadora tanto das interações sociais quanto dos processos de conhecimento de mundo.

Além desse aspecto, as observações cotidianas também propiciaram a percepção de como as experiências anteriores das crianças, que proporcionaram acesso a diferentes linguagens simbólicas criadas pela humanidade e que ampliaram suas experiências e vivências, não são consideradas no currículo do $1^{\circ}$ ano. Entretanto, conforme destaca Rocha (2001, p. 31), "pelas relações sociais múltiplas entre as crianças e destas com diferentes adultos", as culturas vão sendo produzidas, podendo configurar-se em benefícios para os envolvidos nesse processo. Desse modo, as interações na sala e, de modo especial, as interações mediadas pela professora possibilitam perceber que, no ensino fundamental, ainda que nos discursos cotidianos e nos projetos políticos pedagógicos a brincadeira figure como algo especial, a linguagem privilegiada é a escrita e a brincadeira não é concebida como uma linguagem.

Esse fato remete às questões: $\mathrm{E}$ a ludicidade? $\mathrm{E}$ as outras formas de aprender? E as interações, não têm significado? Não há entendimento de que as crianças aprendem com o outro, nas trocas, nas culturas de pares, nas culturas infantis? Onde ficam todas as demais formas de aprendizagens? As tantas outras linguagens que possibilitam outras formas de se compreender a realidade são ignoradas no processo escolar, de modo que as crianças foram evidenciando a apropriação do discurso da professora ou, ousa-se dizer, da própria escola. Assim, as crianças tanto criaram modos de "burlar" as normas instituídas pela escola (copiar sem conversar; não brincar com o material; sentar corretamente; não pedir para ir ao banheiro; levantar a mão para poder falar etc.) como demonstraram a perpetuação do discurso, conforme podemos observar no diálogo entre Gabriela e Felipe: "Gabriela 
olhou para Felipe e disse: 'Olha só, Felipe, você ainda não terminou a atividade. Sabe por quê? Você fica brincando'" (Diário de Bordo, 2014).

Realmente, Felipe se dispersava brincando com um pedaço de plástico que fazia de dentadura para as meninas rirem. Felipe e Gabriela eram os alunos de maior estatura da turma e, por esse motivo, sentavam-se nas últimas carteiras da fila próxima à parede. Sempre que podiam, brincavam, ora com brinquedos que traziam escondidos na mochila, ora transformando em brinquedo seus próprios materiais escolares. Como os dois conversavam em demasia, a professora resolveu trocá-los de lugar, ordenando que Gabriela se sentasse na primeira carteira, bem próxima à sua mesa, "para melhor controlar a tagarelice da menina". Assim, as crianças seguiam: passando de carteira em carteira, dia após dia, semana após semana. Gabriela e Felipe estavam distantes um do outro, porém, havia entre eles uma cumplicidade que se configurava pelas trocas de olhares e sorrisos (sem a professora perceber, é claro!). Eles recorriam a essa estratégia quando queriam ou precisavam extrapolar as regras impostas pelo silêncio.

É importante lembrar que, na escola, a interação ainda é definida pela situação de ensino que envolve professor e alunos numa relação assimétrica, especializada e com uma direção pré-estabelecida, de modo que nada deve perturbar essa ordem (Laplane, 2000). Assim, as relações são complementares: professor é aquele que sabe e, por isso, tem uma posição superior; aluno é aquele que não sabe e, por isso, deve ocupar uma posição de submissão. Trata-se de relações de saber/poder $X$ não saber/não poder. Essa posição do professor garante que ele defina as aulas, organize-as, solicite tarefas, determine tempos, avalie, repreenda.

Não obstante, as observações desmentem essa submissão. As trocas de olhares com os colegas, os intercâmbios verbais, a atividade motora, a transformação do material em brinquedo evidenciam as "estratégias de sobrevivência na sala de aula" (Laplane, 2000, p. 62).

Conforme destaca Laplane (2000), essa sucessão de ações parece enquadrar-se na dinâmica da sala de aula, criando a ilusão de que as crianças estão integradas às atividades escolares. Entretanto, como já demonstrado, uma análise dessas ações e relações desmancha a tácita aparência "ao mostrar que não é possível identificar um propósito 'escolar' que as atravesse" (Laplane, 2000, p. 62).

Observou-se, ainda, que o momento destinado às brincadeiras se transformava em momentos de chantagem e negociações, isto é, premiações ou punições. As crianças deveriam se comportar para ganhar prêmios. Para que o bom comportamento fosse a tônica durante as aulas, a professora usava de subterfúgios, ora premiando com três estrelas, figurinha ou medalhas os melhores em comportamento, ora punindo aqueles que não se enquadravam nas regras escolares. Para estes, a pena era ficar sem o parque, ser encaminhado para a diretoria ou até mesmo ficar sem o recreio, momento tão esperado por todos.

Essa prática demonstra como o modo escolar, aquele que valoriza o corpo dócil, disciplinado e passivo, se sobrepõe ao corpo ativo, curioso da criança. Indica, também, como a professora foi disciplinada, como segue as 
regras que lhe garantem ter uma "boa turma". Esse fato também instiga, a fim de suscitar reflexão, os seguintes questionamentos: como é, para essa professora, manter essa atitude? Quais são seus gastos emocionais? Quais são as suas concepções de criança e de infância? Em outras palavras, essas atitudes reproduzem uma ideologia, um discurso hegemônico, segundo o qual o sujeito, para ganhar prêmios, deve se sujeitar às normas ditadas pelo adulto da relação - nesse caso, a professora.

Um exemplo dessa relação foi observado em um dia, após o intervalo do recreio, na aula de educação física (10/02/2014). A professora iniciou sua aula dizendo para a turma que nunca havia trabalhado com crianças pequenas, o que seria um novo desafio. Com as seguintes palavras, a professora se apresentou às crianças:

Essa é a primeira vez que pego uma turminha de "gente tão pequena". Eu vou precisar que vocês me ajudem. Escutem bem o que a professora vai falar. Vamos colocar umas regrinhas. Quando um amiguinho quiser falar, tem que levantar a mãozinha. Daí a professora vai olhar no seu olhinho e falar com a criança. Nesse momento, a professora perguntou para as crianças: Combinado, isso? Na educação física a gente vai correr, brincar e fazer algumas coisas. Uma das crianças falou (sem ter levantado a mão para pedir para falar). A professora perguntou para a turma: $\mathrm{O}$ que a criança deveria ter feito? E todos responderam em coro: Levantar a mão. E a professora continuou: Agora eu quero ensinar algo para vocês. Venham aqui à frente a Helena, o Felipe, a Mirela e o Lorenzo. A professora perguntou o seguinte: Vocês vieram do "prezinho"? Agora vamos lá! O menorzinho vai dar dois passinhos. Quem é o mais baixinho dá dois passinhos para frente. Agora quem é o maiorzinho que ele? E o próximo? Então, o que nós fizemos? E as crianças responderam em coro: Fila! A professora complementou: Fizemos uma fila por tamanho, na ordem crescente. Agora quero uma fila diferente. Vamos lá, de novo, do grande para o pequeno. A professora deu o comando e as crianças se entreolharam, sem saber direito o que fazer. Vinícius pediu para ir ao banheiro. A professora explicou que ele tem que ir ao banheiro somente no horário do recreio e completou: Hoje você pode ir, por que é o primeiro dia de aula, mas nos outros dias não poderá mais ir. Entendido? Na sequência, a professora se voltou para a aluna Sheila e comentou: Está fazendo o que a professora pediu para não fazer. Eu quero ser sua amiguinha, viu? Então, não vire para a Ana. Por favor, vamos voltar para a fila. (Diário de bordo, 2014).

Dessa forma, a professora orientava as crianças em relação ao posicionamento na fila e ao comportamento esperado e desejado, que obrigatoriamente os alunos deviam seguir. Analisando seu discurso, percebe-se que a professora utilizou termos diminutivos como "amiguinho", "olhinho" e "mãozinha", o que implica, para além de suas ordens, a reflexão: ela pretendia se colocar no mesmo plano das crianças ou diminuí-las? A professora se porta como acessível, como amiga das crianças; em contrapartida, elas têm que se comportar, com obediência e submissão. A criança não tem direito à voz. Afinal, educa-se para a submissão ou para a autonomia? Qual o papel da professora? Quais as ideologias em seu discurso? Repensar o papel social da escola, bem como a relação com a educação infantil, se faz urgente. 
Outro aspecto interessante nesse processo é observar o silêncio das crianças. O silêncio também tem sua função. Pode-se, num primeiro momento, afirmar que o silêncio das crianças evidencia submissão "aos combinados" da professora e às regras da escola; no entanto, quando se analisam as ações, os olhares, os gestos das crianças e o próprio silêncio, afasta-se da noção de interlocução, que se compreende sempre como uma relação de encontro, bem-sucedida. Entende-se o silêncio como interdiscurso, uma vez que ele, na situação relatada, é um elemento que subjaz aos eventos discursivos. Em outras palavras, o silêncio das crianças pode evidenciar que a interação não foi consensual nem bem-sucedida; antes, entende-se que algo foi silenciado.

Essas relações de submissão-subversão foram observadas em outros momentos, como durante a hora do recreio, em que as crianças permaneciam nas mesas de lanche no pátio e não exploravam os demais espaços da escola. No entanto, nesse espaço circunscrito, faziam novas amizades, brincavam e riam muito, numa demonstração de como procuravam adaptar suas necessidades e vontades às regras da escola.

Por vezes, as crianças eram surpreendidas com as cobranças e regras, como no dia em que Davi, após fazer um novo amigo e com ele brincar muito, no retorno à sala de aula, esqueceu seu pote de lanche sobre a mesa. Quando se lembrou, voltou para buscá-lo e, assim, andou pela chuva e se atrasou para entrar na fila. Em sala, a professora encaminhou para a diretoria os meninos que andaram na chuva em razão de sua desobediência. Ela olhou para Davi e perguntou: "Davi, você quer ir para a orientadora?". Ele abaixou os olhos e balançou a cabeça negativamente. E a professora continuou: "Amanhã não quero ver você dando 'piti' e fazendo ceninha". "Como você vai chegar amanhã?". Ele respondeu: "Bom". E a professora reforçou: "Bem bom! Diga: - Bem bom! Não quero mais você se comportando como hoje! Entendeu? Senão vou tirar de você o parque e depois o recreio. Só quem tem a perder é você! Viu?". Ele novamente balançou a cabeça, dessa vez afirmativamente, e se pôs a roer as unhas. Davi mudou seu comportamento. Rapidamente compreendeu seu papel de aluno. Durante os meses em que se prosseguiu a pesquisa, Davi se tornou um aluno exemplar, de acordo com os paradigmas de comportamento da professora. Nas palavras e reflexões de Arroyo (2009, p. 137), instiga-se a seguinte pergunta: o que teria levado "as instituições e pedagogias civilizatórias a terem uma função mais reguladora do que libertadora, o que teria levado ao colapso da emancipação na regulação das infâncias?".

Em outra situação, Ana Flávia (27/02/2014) não conseguira comer toda a pipoca durante o recreio e entrou na sala de aula comendo. A professora pediu que as crianças guardassem suas coisas na mochila e disse que naquele momento não poderiam mais lanchar. Ana Flávia guardou o pacote de pipoca na mochila, mas deixou a mochila semiaberta, de modo que pudesse pegar a pipoca e comer disfarçadamente. Desse modo, Ana Flávia foi driblando as normas instituídas pela escola, comendo sua pipoca sorrateiramente, porém, com o olhar sempre atento aos movimentos da 
professora. Escondida do olhar da professora, ela colocava a mão na mochila, pegava um punhado de pipoca e comia.

Assim, as crianças ora subvertiam, ora acatavam as ordens estabelecidas. Aquelas que cumpriam as regras impostas pela professora eram consideradas boas alunas. É necessário pensar sobre essa subversão infantil, uma vez que não parece demonstrar desconsideração à professora ou ao espaço escolar, como podem ser compreendidos os modos que as crianças encontraram para satisfazer suas necessidades, vontades e desejos. Nesse sentido, Barbosa (2006, p. 40) lembra que, nas atividades do dia a dia, "não somos seres passivos, mas indivíduos que operam comumente sobre o contexto e constroem variações; somos usuários múltiplos, pois o cotidiano se inventa de mil maneiras". Vale ressaltar, conforme destaca Rocha (2008, p. 49), que "ouvir a criança exige a construção de estratégias de troca, de interação, mais do que de perguntas e respostas, pelas quais se nega que as crianças constituem significados de forma independente".

\section{Reflexões finais}

Por mais que o contexto escolar torne as crianças disciplinadas e as transforme em alunos, estar nesse espaço, para elas, é deveras prazeroso. Elas gostam muito de ir à escola, de fazer parte do primeiro ano, de aprender conteúdos apropriados para essa faixa etária. Por mais contraditório que pareça, é dessa forma que as crianças encaram estar no ensino fundamental, com gosto pelo novo, pelas novas experiências, pelos saberes oportunizados àqueles que frequentam essa etapa. Entretanto, conforme se discutiu ao longo do trabalho, essa vivência exige da criança várias criações e estratégias de sobrevivência nesse contexto. Tal fato levanta a seguinte questão: até quando a criança viverá esse caso de amor com o saber? Dito de outro modo:

As relações que um aluno mantém com esse professor são sobredeterminadas: são relações com seu saber, com seu profissionalismo, com seu estatuto institucional, com sua pessoa. Uma vez mais, a questão é importante: o aluno pode atribuir outros sentidos a uma relação definida, em princípio, como relação de saber (o professor também, aliás). (Charlot, 2000, p. 67).

Nesse aspecto, a pesquisa tendo como objetivo analisar a passagem da educação infantil para o ensino fundamental compreende que a criança não apenas percebe seu processo de transição, mas também deseja fazer parte do processo de escolarização, bem como apreciar o que significa estar nessa instituição. Além da apropriação do ler e do escrever, outra força propulsora apresentada pelas crianças foi a valorização do mundo adulto, ancorada no fato de estarem crescendo. Nas falas das próprias crianças, aprender a ler é um atributo de "ser grande". Nesse sentido, Sacristán (2005, p. 182) afirma que: 
[...] as práticas de leitura e escrita nas escolas adquirem formas e um significado especial; por isso socializam o leitor-aluno de uma forma singular. As modalidades de ler e escrever nas salas de aula se constituem em modos de ter acesso à cultura e em modos de ser pessoa.

Dito de outro modo, ir à escola significa mais do que estar crescendo, significa fazer parte do mundo letrado. A valorização demonstrada pelas crianças por estarem nesse outro espaço, com outras práticas pedagógicas, bem como por participarem de outras experiências, foi constantemente confirmada por várias falas e episódios observados durante a pesquisa. Entretanto, novamente surgem inquietações, pois, de acordo com Charlot (2000, p. 69):

O corpo é um lugar de apropriação do mundo, um "conjunto de significações vivenciadas", um sistema de ações em direção ao mundo, aberto às situações reais, mas também virtuais. O corpo é o sujeito enquanto engajado no "movimento da existência", enquanto "habitante do espaço e do tempo".

Conforme foi discutido, o corpo é secundarizado na escola, especialmente, na sala de aula. Esse fato gerou nas crianças várias ações, como sentar de diferentes maneiras, levantar para apontar lápis, solicitar ajuda da professora indo até sua mesa, ficar escrevendo em pé, pedir para ir ao banheiro, entre outras ações que evidenciaram tanto a necessidade de participação do corpo nesse processo como as estratégias das crianças para se adequarem ao novo lugar, tão desejado e tão socialmente valorizado. Nesse sentido, Motta (2013) esclarece que

A forma de utilização do próprio corpo revelava uma aprendizagem; a sala de aula, no ensino fundamental, era um espaço no qual os movimentos deviam ser mais contidos, as vozes deveriam ser reguladas num volume mais baixo, os movimentos não autorizados ou não participantes das ações escolarizadas deveriam ser feitos de maneira rápida e sutil, preferencialmente quando a professora não estivesse atenta aos envolvidos na comunicação. Percebe-se aqui uma sujeição dos corpos infantis à lógica das culturas escolares que conformam um tipo de subjetividade bem específica: a do aluno. (Motta, 2013, p. 128).

Essas reflexões indicaram a urgência em se pensarem práticas pedagógicas que promovam "a construção da autonomia moral e intelectual das crianças, estimulando sua curiosidade" (Barbosa; Horn, 2008, p. 50). Deve-se pensar em práticas que possibilitem à criança desenvolver ideias a respeito das coisas ao seu redor e do mundo do qual faz parte, promovendo interações cada vez mais complexas e problematizadoras. Faz-se importante lembrar que a pesquisa evidenciou que, embora algumas práticas sejam comuns à educação infantil e à escola (por exemplo: dia do brinquedo, hora de parque), o modo como essas práticas são mediadas é diferente, isto é, em apenas dois meses de separação entre educação infantil e ensino fundamental, há uma intensificação da burocratização das relações. Assim, o brincar se apresenta muito mais como uma estratégia de "tornar o $1^{\circ}$ ano menos cansativo" do que um reconhecimento dessa linguagem no desenvolvimento e na aprendizagem humana. 
A interação entre os pares, no ensino fundamental, restringia-se praticamente ao recreio, pois, em sala de aula, se havia interações, estas ocorriam quando as crianças transgrediam as ordens pré-estabelecidas. Houve momentos em que as crianças reclamavam do excesso e da repetição de atividades e constantemente demonstravam cansaço e tédio. Falas foram silenciadas pela professora e pela própria cultura escolar. Assim, não havendo outra maneira de articulação pelos sujeitos-crianças, o que lhes restava era subverter a ordem institucionalizada para que, dessa forma, pudessem vivenciar experiências próprias do universo infantil.

Nesse sentido, conforme Faria (2012, p. 45, grifo da autora) destaca, é importante pensar o fazer pedagógico em sua cotidianidade, utilizando-se de estratégias que oportunizem para as crianças a continuidade no seu processo de desenvolvimento e aprendizagens, "facilitando-lhes vivenciar esse 'ritual de passagem' sem causar rupturas que provoquem, nelas e em suas famílias, ansiedade e insegurança".

A partir da pesquisa, também foram possíveis algumas reflexões sobre as políticas voltadas à educação, especialmente à educação para a infância. Ainda que os documentos oficiais tenham indicado e indiquem a elaboração de uma nova proposta curricular para o ensino fundamental de nove anos e que estudos atentem para o cuidado em não converter essa modificação do ensino em uma mera ação administrativa, a pesquisa evidenciou que essas observações não foram totalmente seguidas. De modo similar, apesar de os discursos escolares indicarem a importância da articulação entre os níveis educativos e de um ambiente acolhedor para as crianças, na cotidianidade o observado é ainda segmentação e desarticulação entre esses dois níveis.

Assim, entende-se que segue ainda como desafio assegurar as aprendizagens de cada um, sem homogeneizá-las, mas compreendendo a heterogeneidade de crianças advindas de classes sociais igualmente diferenciadas. Nas palavras de Motta (2013, p. 176):

[...] cada um desses sujeitos deve ser visto numa dupla dimensão: de um lado pessoas concretas, com suas agruras e suas bem-aventuranças; de outro, personagens de uma história que não cessa de acontecer a cada ano, em cada turma escolar.

Além disso, é importante lembrar que

[...] num país como o nosso, onde a desigualdade e a injustiça social são constitutivas da história e do cotidiano, conquistas resultam de muito trabalho realizado e - para que não se reduzam à letra morta, indicam sempre que há muito trabalho a fazer. (Rocha, E. A. C.; Campos, R.; Campos, R. F., 2009, p. 212).

Dessa forma, as falas das crianças indicaram a necessidade de as diversas instâncias responsáveis pelas políticas, tanto no contexto da elaboração quanto no contexto da prática, atuarem de modo articulado, pois as análises dos dados demonstraram que a ampliação do tempo escolar (ensino fundamental de nove anos, com matrícula aos seis anos) como 
medida isolada não promoveu a construção da escola democrática almejada, tampouco garantiu uma educação de qualidade às crianças (Rocha, E. A. C.; Campos, R.; Campos, R. F., 2009).

\section{Referências bibliográficas}

ARROYO, M. A infância interroga a pedagogia. In: SARMENTO, M.; GOUVEA, M. C. S. de (Org.). Estudos da infância: educação e práticas sociais. 2. ed. Petrópolis: Vozes, 2009. p. 119-140.

BARBOSA, M. C. S. Por amor e por força: rotinas na educação infantil. Porto Alegre: Artmed, 2006.

BARBOSA, M. C. S.; HORN, M. da G. S. Projetos pedagógicos na educação infantil. Porto Alegre: Grupo A, 2008.

CARVALHO, A. F.; MÜLLER, F. Ética nas pesquisas com crianças: uma problematização necessária. In: MÜLLER, F. (Org.). Infância em perspectiva: política, pesquisa e instituições. São Paulo: Cortez, 2010. p. 65-84.

CHARLOT, B. Da relação com o saber: elementos para uma teoria. Porto Alegre: Artmed, 2000.

FAIRCLOUGH, N. Discurso e mudança social. Coordenação da tradução, revisão técnica e prefácio de Izabel Magalhães. Brasília, DF: Ed. UnB, 2001.

FARIA, V. L. B. de. Currículo na educação infantil: diálogo com os demais elementos da proposta pedagógica. 2. ed. rev. e ampl. São Paulo: Ática, 2012. (Educação em Ação).

FREIRE, P. Pedagogia da autonomia: saberes necessários à prática educativa. 44. ed. Rio de Janeiro: Paz e Terra, 2013.

KRAMER, S. As crianças de 0 a 6 anos nas políticas educacionais no Brasil: educação infantil e/é fundamental. Revista Educação \& Sociedade, Campinas, v. 27, n. 96 esp., p. 797-818, out. 2006. Disponível em: $<$ http://www.scielo.br/pdf/es/v27n96/a09v2796>. Acesso em: 22 jan. 2014 .

LAPLANE, A. L. F. Interação e silêncio na sala de aula. Cad. CEDES, Campinas, v. 20, n. 50, p. 55-69, 2000. 
LÜDKE, M.; ANDRÉ, M. E. D. A. Pesquisa em educação: abordagens qualitativas. São Paulo: EPU, 1986.

MOTTA, F. M. N. De crianças a alunos: a transição da educação infantil para o ensino fundamental. São Paulo: Cortez, 2013.

ROCHA, E. A. C. A pedagogia e a educação infantil. Revista Brasileira de Educação, Rio de Janeiro, n. 16, jan./abr. 2001.

ROCHA, E. A. C. Por que ouvir as crianças? Algumas questões para um debate científico multidisciplinar. In: CRUZ, S. H. V. C. (Org.). A criança fala: a escuta de crianças em pesquisas. São Paulo: Cortez, 2008. p. 43-51.

ROCHA, E. A. C.; CAMPOS, R.; CAMPOS, R. F. Ensino Fundamental de nove anos: continuidade ou rupturas com as políticas de focalização no ensino fundamental? In: VASQUES, C.; SCHLICKMANN, M. S. P.; CAMPOS, R. (Org.). Educação e infância: múltiplos olhares, outras leituras. Ijuí: Unijuí, 2009. p. 197-216.

SACRISTÁN, J. G. O aluno como invenção. Porto Alegre: Artmed, 2005.

SANTOS, L. D. N. dos; BOLZAN, D. P. V. O ingresso da criança aos seis anos na escola obrigatória: reflexões acerca das práticas escolares. In: FERREIRA, V. S.; GESSER, V. (Org.). Ensino Fundamental de nove anos: princípios, pesquisas e reflexões. Curitiba: CRV, 2013. 184 p.

Recebido em 18 de novembro de 2014.

Solicitação em correções 27 de maio de 2015.

Aprovado em 12 de junho de 2015. 